\title{
Pneumocystis pneumonia in the twenty-first century: HIV-infected versus HIV-uninfected patients
}

\section{Catia Cillóniz, Cristina Dominedò, Míriam J Álvarez-Martínez, Asunción Moreno, Felipe García, Antoni Torres \& José M Miro}

To cite this article: Catia Cillóniz, Cristina Dominedò, Míriam J Álvarez-Martínez, Asunción Moreno, Felipe García, Antoni Torres \& José M Miro (2019): Pneumocystis pneumonia in the twenty-first century: HIV-infected versus HIV-uninfected patients, Expert Review of Anti-infective Therapy, DOI: $\underline{10.1080 / 14787210.2019 .1671823}$

To link to this article: https://doi.org/10.1080/14787210.2019.1671823

Accepted author version posted online: 25

Sep 2019.

Submit your article to this journal $₫$

Q View related articles ¿

View Crossmark data 
Publisher: Taylor \& Francis \& Informa UK Limited, trading as Taylor \& Francis Group

Journal: Expert Review of Anti-infective Therapy

DOI: $10.1080 / 14787210.2019 .1671823$

Article type: Review

Pneumocystis pneumonia in the twenty-first century: HIV-infected versus HIVuninfected patients

Catia Cillóniz ${ }^{1}$, Cristina Dominedò ${ }^{2}$, Míriam J Álvarez-Martínez ${ }^{3}$, Asunción Moreno ${ }^{4}$, Felipe García ${ }^{4}$, Antoni Torres* ${ }^{1}$, José M Miro ${ }^{4}$

${ }^{1}$ Department of Pneumology, Hospital Clinic, Barcelona; August Pi i Sunyer Biomedical Research Institute (IDIBAPS); University of Barcelona; SGR 911; Biomedical Research Networking Centres in Respiratory Diseases (CIBERES), Barcelona, Spain

${ }^{2}$ Department of Anesthesiology and Intensive Care Medicine, Fondazione Policlinico Universitario A. Gemelli, Università Cattolica del Sacro Cuore, Rome, Italy

${ }^{3}$ Department of Microbiology, Hospital Clinic, Barcelona; University of Barcelona, Barcelona, Spain

${ }^{4}$ Department of Infectious Diseases, Hospital Clinic, Barcelona; IDIBAPS; University of Barcelona, Barcelona, Spain

*Corresponding author:

Antoni Torres

Department of Pneumology, Hospital Clinic, Barcelona

C/ Villarroel 170, 08036 Barcelona, Spain

Phone: 0034932275549

Email: atorres@clinic.cat 


\section{Abstract}

Introduction: Pneumocystis pneumonia (PcP) has classically been described as a serious complication in patients infected with the human immunodeficiency virus (HIV). However, the emerging number of conditions associated with immunosuppression has led to its appearance in other patient populations, such as those receiving chronic corticosteroid therapy, those with hematological or solid malignancies, transplant recipients and those who receive immunomodulatory or biological therapy.

Areas covered: This article reviews the most recent publications on PcP in the HIVinfected and HIV-uninfected population, focusing on epidemiology, diagnostic, therapy and prevention. The data discussed here were mainly obtained from a non-systematic review using Medline and references from relevant articles including randomized clinical trials, meta-analyses, observational studies and clinical reviews. Eligible studies were selected in two stages: sequential examination of title and abstract, followed by full text.

Expert opinion: Widespread use of antiretroviral and prophylactic therapy in HIVinfected patients has decreased the incidence of PcP in this population. However, the growing incidence of Pneumocystis infection in the HIV-uninfected population suggests the need for new global epidemiological studies in order to identify the true scale of the disease in this population. These data would allow us to improve diagnosis, therapeutic strategies, and clinical management. It is very important that both patients and physicians realize that HIV-uninfected patients are at risk of PcP and that rapid diagnosis and early initiation of treatment are associated with better prognosis. Currently, in-hospital mortality rates are very high: $15 \%$ for HIV-infected patients and $50 \%$ in some HIV-uninfected patients. Therefore, adequate preventive measures should be implemented to avoid the high mortality rates seen in recent decades. 


\section{Article highlights}

- Pneumocystis is prevalent in the lungs of immunocompetent individuals, suggesting that asymptomatic healthy adult carriers provide a reservoir for Pneumocystis infection.

- In HIV-infected patients the risk for PcP increases exponentially when the CD4+ cell count is below 200 cells/ $\mu$ l. Patients on ART who develop PcP typically have low CD4+ cell levels due to poor adherence to ART or possible resistance to ART.

- There is a growing incidence of Pneumocystis infection in the HIV-uninfected population due to the emerging number of conditions associated with immunosuppression. These include hematological malignances, solid tumors, solid-organ transplantation, autoimmune diseases, steroids therapy, immunosuppressive or biological therapy.

- There is strong evidence of the presence of Pneumocystis in the air of areas where infected patients reside and of a transmission through interpersonal contacts. It is reasonable to isolate infected patients until respiratory symptoms resolution or discharge from hospital; when patients need to be moved a mask should be worn. 


\section{Introduction}

In the last decade the number of immunocompromised patients has increased globally[1,2]. Patients with immunosuppression show an increased risk of pulmonary infectious complications like Pneumocystis pneumonia (PcP). Indeed, the risk of PcP and other fungal infections is elevated in patients with human immunodeficiency virus (HIV) infection, chronic corticosteroid use, hematological or solid malignancies, organ transplantation and immunomodulatory or biological therapy, although the data regarding prevalence come from a small number of patients in single-center or singlecountry studies [3-5]. (Figure 1).

Pneumocystis jirovecii is probably transmitted via environment aerosols from infected patients or colonized individuals[6]. The global incidence of PcP is unclear due to its non-specific symptoms, the difficulty to obtain good respiratory samples and to perform microbiological diagnosis. Delayed or missing PcP diagnosis may compromise the early initiation of an adequate therapy, thus increasing the risk of poor outcomes. Because of the widespread use of antiretroviral and prophylactic therapy in HIVinfected patients, the incidence and mortality of PcP has fallen in recent decades[7]. However, several studies still report high mortality rates among HIV-uninfected patients probably due to the greater intensity of the inflammatory response, the acuteness of symptoms, the more frequent progression to respiratory failure requiring tracheal intubation [8], and also the influence of different management practices[913].

The aim of this review is to present and discuss recent advances in our understanding of PcP in HIV-infected and HIV-uninfected patients. We focus principally on its epidemiology, clinical presentation, diagnosis, colonization and risk factors. We believe 
that this information will help to identify patients at risk and will help in the diagnosis of PcP, especially in HIV-uninfected patients, in order to initiate prompt therapy.

\section{Transmission}

Pneumocystis jirovecii is an obligate fungal organism with high tropism for the alveolar epithelium of the lung. Generally, it attaches to cells without invading them, thus showing a parasitic behavior[9]. Trophic and cystic forms have been identified in its life cycle, with trophic forms predominating over the cystic ones during lung infections[14]. Unfortunately, the inability to culture Pneumocystis outside the lung limits the complete comprehension of its life cycle $[15,16]$. Pneumocystis rarely causes disseminated infections, although some cases have been reported in patients with AIDS[17,18].

Infection generally occurs in immunosuppressed patients due to the acquisition of a new infection rather than the reactivation of a latent one. In a rat model of prior PcP episodes, animals did not present reactivation of Pneumocystis infection when immune suppression was induced, unless they have been exposed to other rats with active infection[19]. Interestingly, the latency model of infection in humans by Wakefield et al.[15] (which used 47 bronchoalveolar lavage samples from 16 HIVinfected patients) showed that after a PcP episode in HIV-infected patients asymptomatic carriage of Pneumocystis did not last longer than 9.5 months.

Pneumocystis transmission has been understood to be interindividual. It has been hypothesized that $P$. jirovecii is generally transmitted via the airborne route (17-20), 
although no established reservoir has been identified so far and several possible routes of transmission have been considered. Nosocomial interhuman transmission is one possibility, with Rabodonirina et al.[24] demonstrating the pathogen transmission between HIV-infected patients with PCP and hospitalized renal transplant recipients. Yazaki et al.[25] investigated the environmental exposure as a possible route of Pneumocystis transmission following an outbreak of PcP in renal transplant recipients. The authors detected in outpatients consulting rooms $P$. jirovecii deoxyribonucleic acid (DNA) with the same genotypes as in clinical samples obtained two months earlier. Finally, data on Pneumocystis colonization in immunocompetent[26-29] or physiologically immunosuppressed individuals (e.g., pregnant woman)[30] have led to the hypothesis that these groups may act as contagious sources for susceptible persons, making them possible reservoirs in the community[14]. Mother-to-infant transmission of $P$. jirovecii has also been described. In a pilot study of 33 third-trimester, pregnant, asymptomatic healthy women (median age 26 years) and 28 controls (healthy women within 15 days of a menstrual period; median age 28 years). Vargas et al.[30] detected $P$. jirovecii DNA in deep nasal swab samples in five $(16 \%)$ of the 33 pregnant women but in none $(0 \%)$ of the controls. Thus explaining why primary Pneumocystis infection can be acquired early in life (i.e., through vertical transmission). Montes-Cano et al.[31] analyzed placentas and lungs of 20 fetuses at 28 \pm 8 weeks of gestation. $P$. jirovecii was observed in lung tissue samples from 7 (35\%) fetuses, thus confirming the possibility of a trans placental transmission in humans. Interestingly, the study by Rojas et al.[32]. that investigated the prevalence of $P$. jirovecii colonization in 128 preterm infants and its possible association with medical complications reported that Pneumocystis DNA was presented in $26 \%$ of the newborns 
studied. The authors suggested that $P$. jirovecii colonization could be a risk factor for ARDS in preterm infants.

\section{Focusing on colonization}

Colonization or subclinical infection with $P$. jirovecii is defined as the isolation of $P$. jirovecii in respiratory samples in patients with no specific symptoms or history of PCP. Interstitial pneumonia is the major clinical manifestation in patients with active infection for $P$. jirovecii [6].

Several studies have identified possible colonization in both HIV-infected and HIVuninfected patients $[6,14,26,28,29]$. Colonization influences interindividual transmission of the pathogen, appearance of lung inflammation and damage, progression of the disease and development of resistance.

\subsection{Colonization in immunocompetent individuals}

A prospective Spanish study [33] was designed to determine whether $P$. jirovecii can be detected in the normal, healthy population. It investigated oropharyngeal wash samples from 50 persons who had not been exposed to patients in a hospital environment within the year before the study, or who had not been diagnosed with, or were not suspected to have, chronic lung disease, neoplasm, or immunosuppression of any cause. P. jirovecii DNA was present in $24 \%$ of cases. All carriers were asymptomatic, HIV-uninfected and had normal total lymphocyte and CD4+ cell counts. Similarly, in a study of the detection of $P$. jirovecci DNA in oropharyngeal wash and nasal swab samples from 110 immunocompetent older adults (>65 years), Vargas et al.[34] reported that $P$. jirovecii DNA was detected in $13 \%$ of oropharyngeal wash samples and in $11 \%$ of the nasal swab samples. However, taking the orophayngeal 
wash and nasal swab samples together, the rate of detection rose to $22 \%$.

Interestingly, the authors reported that none of the participants developed PcP within 1 year of study completion. As the above studies reported, Pneumocystis is frequently detected in the respiratory tract of immunocompetent individuals, suggesting that asymptomatic healthy adult carriers provide a reservoir for Pneumocystis infection[33,34].

\subsection{Colonization in patients with Chronic Lung Diseases}

Several studies have reported Pneumocystis colonization in individuals with chronic lung diseases (chronic obstructive pulmonary disease [COPD], cystic fibrosis, chronic bronchitis, and asthma)[35,36]. Some of these studies have also found an association between lung disease progression and colonization with Pneumocystis. In a study of Pneumocystis colonization rates in lung tissue obtained during lung resection or transplantation in smokers with a range of airway obstruction severity and in a control group with lung diseases other than COPD, Morris et al.[35] found Pneumocystis colonization in $36.7 \%$ of patients with very severe COPD and in $5.3 \%$ of smokers with normal lung function or less severe COPD. Colonized individuals presented more severe airway obstruction (median FEV $(1)=21 \%$ predicted versus $62 \%$ in noncolonized subjects, $p=0.006)$. The authors found that the Global Health Initiative on

Obstructive Lung Diseases (GOLD) GOLD IV classification[37] was the strongest predictor of Pneumocystis colonization (odds ratio: 7.3, 95\% confidence interval $=2.4$ to $22.4, p<0.001$ ) and was independent of smoking history. An interesting study on the distribution of Pneumocystis colonization in the lungs of patients with COPD was published in 2011[36]. The authors examined the explanted 
lung tissue of 19 patients with COPD and without HIV infection who underwent lung transplantation. Pneumocystis colonization was detected in $42 \%$ of patients with advanced COPD. Colonization was more frequent in the lower and middle lobes than in upper lobes. According to the authors, these differences in the distribution of colonization may be due to the lower sensitivity of Pneumocystis detection in the upper lobes of COPD patients because the disease has already become end-stage in these areas of the lung, or because these areas have lower tissue content. The authors also tentatively attributed the relative propensity for lower lobe colonization to the greater ventilation in the lower regions of the lung than in the upper regions. The authors suggested that the use of a single sample from an individual might underestimate the prevalence of Pneumocystis colonization[36].

\subsection{Colonization in patients with Immunosuppression}

There is significant variability regarding the rate of Pneumocystis colonization in patients with HIV, with studies reporting rates between $6 \%$ and $68 \%[6,38-41]$. This variation reflects differences in the study populations, biological samples and microbiological tests. Gutierrez et al.[42] analyzed the prevalence of $P$. jiroveci colonization in oropharyngeal wash samples in a cohort of 20 young HIV-infected patients and found colonization in $40 \%$ of the population; after 50 weeks of follow-up, only one colonized patient with advanced immunosuppression developed PcP. Mekinian et al.[43] analyzed Pneumocystis colonization in 67 patients with systemic autoimmune diseases and 28 controls (healthy subjects). None of the selected patients had respiratory or general signs of current Pneumocystis infection but the authors found that $16 \%(n=11)$ of the patients with systemic autoimmune diseases had 
evidence of colonization, compared with $7 \%(n=2)$ in the control group. The authors also analyzed the risk factors for colonization in patients with systemic autoimmune diseases, finding that male gender was the only risk factor. However, after a new analysis with nested models the authors were able to attribute the difference in the $P$. jirovecii colonization to the higher level of induced immunosuppression in the male patients, as suggested by lymphocyte counts and corticosteroid volume.

\section{Infection}

\subsection{Risk Factors in HIV-infected patients}

Incidence of PcP infection in HIV-infected patients fell substantially with the widespread use of active antiretroviral therapy (ART), especially in developing countries[44]. Most cases of PcP now occur in patients who have undiagnosed HIV infection, who are not receiving ART or who are not adhering to ART at the time of PcP diagnosis, or in cases of sub-optimal immune recovery [45-47]. The risk for PcP increases exponentially when the CD4+ cell count is below 200 cells/ $\mu$ l[17]. Patients on ART who develop PcP typically have low CD4+ cell levels due to poor adherence to ART or possible resistance to ART[46]. When in patients on ART the CD4+ cell count (> 200 cells/ $\mu \mathrm{l}$ ) increases, the risk for PcP decreases sufficiently to safely discontinue both primary and secondary prophylaxis $[17,48]$.

Recent global estimates report that approximately more than 400,000 cases of PcP in patients with acquired immunodeficiency syndrome (AIDS) occur each year $[49,50]$. The case fatality rate is approximately $15 \%$ in patients with AIDS, despite optimal treatment [51]. Interestingly, a systematic review and meta-analysis of the prevalence of PcP in HIV-infected patients in sub-Saharan Africa between 1995 and 2015[52] 
showed a fall in the prevalence of PcP from 28\% to 9\% after 2005.

The overall annual incidence of PcP in HIV-infected adults ranges from 0.9 to 5.4 cases per 1000 person-years [5,53,54]. In the United States and Canada, a recent study of 16 large cohorts of HIV-infected patients showed a fall in the incidence of PcP from 0.92 events/100 person-years in 2000-2003 to 0.39 events/100 person-years in 2008-2010 [9]. Similarly, a Spanish study [45] of 136 PcP cases indicated a significant reduction in the annual incidence of PcP from 13.4 to 3.3 cases per 1000 HIV-infected patients per year during the period between 2000 and 2013. However, the proportion of patients with PcP before a diagnosis of HIV also rose from 48\% in 2000 to $67 \%$ in 2013, confirming that PCP remains an important health problem in patients with HIV[45].

Certainly, the use of ART has influenced the incidence of PCP. Reporting trends in AIDSdefining opportunistic illnesses over a 25 year period (1987-2012) in Brazil, Coelho et al.[56] found a significant reduction in the incidence of PcP from 87.2 to 2.84 cases/1000 person-years between the periods $1987-1990$ and 2009-2012. The authors observed that the use of ART increased over these years, with almost $80 \%$ of patients receiving ART in the latter period.

The mortality rate associated with PcP in HIV-infected patients is reported to be $15 \%$, ranging from $4 \%$ to $32 \%$ on the basis of the population studied, the underlying chronic diseases, the immunological status and the precocity of diagnosis $[7,51]$. Several risk factors have been related to mortality in HIV-infected patients: older age, subsequent episodes of PcP, low haemoglobin level and low basal $\mathrm{PaO}_{2}$ at hospital admission, pulmonary Kaposi sarcoma and pre-existing comorbidities[57,58]. However, recent studies indicate a decrease in PcP-related mortality $[7,59]$. 


\subsection{Risk Factors in HIV-uninfected patients}

PcP is emerging as an important infectious disease in HIV-uninfected persons $[4,13]$. It is estimated that the annual incidence of PcP in this population exceeds 100,000 cases globally, that the case fatality rate is about $50 \%$ and that there are more than 50,000 related deaths[49]. The conditions most frequently associated with an increased risk of PcP are:

*Hematological malignancies (especially leukemia and lymphomas): in this population risk factors related to PcP include the use of corticosteroids, monoclonal antibody therapy, or T-cell dysfunction related to underlying disease or therapy.

*Solid tumors (e.g., brain, breast, lung, and renal): it is reported that the main risk factors in this population are the high-dose chemotherapy and marrow transplantation, and the prolonged use of corticosteroid therapy.

*Solid-organ transplantation: in this population, the main risk for Pneumocystis infection is CD4+ lymphocytopenia.

*Autoimmune diseases (e.g., rheumatoid arthritis, inflammatory bowel diseases and ankylosing spondylitis): in this population, low CD4+ cell count and the use of antiTNF $\alpha$, rituximab or cyclophosphamide may increase the risk.

* Patients receiving steroid, immunosuppressive or biological therapy (anti-tumor necrosis factor [TNF], anti-interleukin 6, anti-interleukin 1, anti-cd52, or anti-CD20) are also at increased risk [60-62].

Hematologic populations at highest risk of PcP are those with acute lymphoblastic leukemia and those who have received allogeneic hematopoietic stem cell 
transplantation (HSCT)[63]. The nationwide study in the UK by Maini et al.[5] analyzed data from 2258 cases of PcP over a decade (2000-2010) and showed an increase in the incidence of $\mathrm{PcP}$, particularly in patients who had an hematologic malignancy or who had undergone transplantation. The number of cases rose from 157 in 2000 to 352 in 2010 (a mean annual increase of 9\%). The authors attribute this increase to the improvements in diagnostic methods over the study period. With regard to the increased transmission of the $P$. jirovecii organism between susceptible persons, the authors suggest that the levels of exposure of susceptible persons to infectious persons may rise as a result of changes in the delivery of health care. Other possible reasons mentioned are the increase in the number of potentially vulnerable patients who did not receive appropriate prophylactic therapy, and an increase in the use of potent immunosuppressant agents in several medical conditions.

In 2014 an interesting French study on the incidence of PcP was published by Fillatre et al.[64]]. The study was carried out between 1990 and 2010 and 293 cases of PcP were detected, 154 (52\%) of which in HIV-uninfected patients. The main underlying conditions associated with PcP were hematological malignancies (32\%), solid tumors (18\%), inflammatory diseases (15\%), solid-organ transplantation (12\%) and vasculitis (10\%) (Figure 1). The authors grouped the risk and the incidence of PcP into three categories according to the underlying diseases or conditions:

- Low risk (incidence $<25$ cases/100,000/patient-years): inflammatory diseases, Hodgkin lymphoma, and other solid tumors.

- Intermediate risk (incidence 25-45 cases/100,000/patient-years): Waldenström macroglobulinemia, multiple myeloma, and central nervous system cancer. 
- High risk (incidence $>45$ cases/100,000/patient-years): polyarteritis nodosa, granulomatosis with polyangiitis, polymyositis/dermatopolymyositis, acute leukemia, chronic lymphocytic leukemia, and non-Hodgkin lymphoma.

Recently, a French study [65] proposed a score to predict the risk of Pneumocystis infection in patients with hematological malignancies and acute respiratory failure (ARF) requiring ICU admission. Variables included in the score were age ( $<50$ [ 1 point]; 50-70 [-1.5 points]; >70 [-2.5 points]), lymphoproliferative disease ( 2 points), antiPneumocystis prophylaxis (1 point), respiratory symptom duration ( $<3$ days [0 point]; 3 to 5 days [ 3 points]; $>5$ days [ 3 points]), shock ( -1.5 points), chest radiograph pattern (2.5 points) and pleural effusion (-2 points). The cut-off score for the definition of pneumocystis was three points. The score showed a specificity of $88 \%$ and a negative predictive value of $97 \%$ of for PcP. The authors expect this score to accelerate the initiation of anti-PcP therapy.

Mortality remains higher in HIV-uninfected patients than in HIV-infected patients $(40 \%-60 \%[62,64]$ and $5 \%-15 \%[7,66]$ respectively), probably due to the higher inflammatory response, the acute presentation of symptoms, the rapid progression to respiratory failure with the need for invasive mechanical ventilation [8] and the different management practices. Mortality in intensive care unit (ICU) is very high for HIV-uninfected patients with PcP. A study of 82 patients with PcP admitted to ICU showed a mortality rate of $76 \%$, with the main risk factors being increased age, raised white blood cell counts and the presence of a pneumomediastinum [12].

\section{Clinical manifestation and outcomes of PcP}


Table 1 summarizes the clinical presentation, radiographic features and outcomes of PcP in HIV-infected and HIV-uninfected patients. HIV-infected patients typically show a sub-acute onset of the infection, longer symptoms duration ( 3 weeks), low-grade fever with progressive dyspnea and less severe course with a mortality rate of $15 \%[46,51,67]$. HIV-uninfected individuals, by contrast, typically have a rapid onset, fast progression to respiratory failure, shorter symptoms duration (4-7 days) , are more likely to require ICU admission and fulminant course with a mortality rate of $30 \%-60 \%$. The different clinical presentation is not associated with the pulmonary fungal load; in fact, it seems to be related to pneumonia severity and the degree of lung inflammation. Limper et al. found that patients with PCP and AIDS have more Pneumocystis organisms and fewer neutrophils in the lung than immunocompromised patients with PcP without AIDS (with the exception of organ transplant patients), and that inflammation in the lower respiratory tract (as measured by the number and percentage of lavage neutrophils and not by microorganism number) is associated with greater impairment of gas exchange and lower patient survival in PcP with and without AIDS [68].

Roux et al. [51] reported clear differences in the clinical features of PcP between 223 patients with AIDS and 321 patients with other immunosuppressive disorders (nonAIDS patients). Patients without AIDS had significantly shorter median times from symptom onset to presentation ( 5 days, compared with 21 days for patients with AIDS; $\mathrm{p}<0.001)$, hypoxemia was more severe; ICU admission was more common ( $50 \%$ vs. $35 \% ; p=0.001)$, and both non-invasive ( $16 \%$ vs. $8 \% ; p=0.005)$, invasive $(30 \%$ vs. $11 \%$; $p=0.001)$ mechanical ventilation were required more often and lower in-hospital mortality ( $4 \%$ vs. $27 \% ; p=0.001)$. These results were in accordance with a recent 
published study from Portugal that assessed the differences between $75 \mathrm{HIV}$ and 54 non-HIV patients with PcP. The authors reported that the clinical presentation in nonHIV patients was more tenuous (respiratory complaints: $67 \%$ vs $37 \%, p=0.002$ ), but with worse outcomes than in HIV-infected patients (in-hospital mortality: $10 \%$ vs $20 \%$, $p=0.002)[69]$.

\section{ART and the Immune Reconstitution Inflammatory Syndrome in PcP}

The immune reconstitution inflammatory syndrome in PcP (PcP-IRIS) is an exaggerated pulmonary immune reaction occurring in HIV-infected patients after ART starting in response to Pneumocystis infection, mediated by the immune system recovery [70]. PCP-IRIS has been associated with high morbidity and ICU admission but mortality rates are very low; the reason for this lower mortality could be the fact that the patients received corticosteroids, which have immunomodulatory properties and may regulate the inflammatory storm of IRIS, or that these patients are on PcP therapy which reduces the Pneumocystis load [71-74]. The timing of PcP-IRIS presentation in relation to ART initiation dictates its further definition: "paradoxical IRIS" refers to a worsening of symptoms secondary to Pneumocystis infection after ART starting and treatment for PcP, whereas "unmasked IRIS" refers to Pneumocystis infection that is undiagnosed before ART. Although the onset of PCP-IRIS is variable, it usually occurs within 3 months of ART starting [70].

The true incidence of PcP-IRIS remains unclear because most data have come from case reports[71,75]. A retrospective study in the USA by Achenbach et al.[76] on patients suffering opportunistic infections after ART starting reported that IRIS occurred in $4 \%$ of patients with Pneumocystis infection within 1 year. 
Early initiation of ART does not affect the incidence of PCP-IRIS[77]. Also, according to clinical trial data for the optimal timing of ART initiation in AIDS-related opportunistic infections (OI), it is recommended to start ART therapy within two weeks of OI treatment initiation when there is co-infection with PcP [78].

Clinically, PcP-IRIS presents as a worsening of existing PcP or an unmasking of PcP[72]. Most patients display an inflammatory response upon starting therapy directed against Pneumocystis, which is tempered by treatment with corticosteroids; however, some patients develop a worsening of pulmonary disease after starting ART, presenting fever, dyspnea and worsening hypoxia. The common radiological manifestations in PcP IRIS are the presence of ground glass opacities, but in some cases atypical radiological manifestations such as consolidations, organization pneumonia, and absence of effusion and nodes have been reported [70]. Currently, the consensus is to continue with ART due to the possibility that HIV replication progresses, but to start specific treatments for any co-infection[17].

\section{Radiographic features}

HIV-infected patients generally present bilateral interstitial and alveolar infiltrates in perihilar areas (Figure 2, a, b). Conversely, HIV-uninfected patients generally show diffuse lung infiltrates and evident consolidations, with few cases presenting pulmonary cysts or pneumatoceles (Figure 2, c, d). Radiographic chest patterns are not-specific in general. Several studies have described the role of the High Resolution Computed Tomography (HRCT) of the chest in the diagnosis of PcP in HIV-infected and HIV-uninfected patients[79-82]. 
The study by Fuji et al.[79] described the clinical features of 34 episodes of PcP in 32 HIV-infected patients. HRCT of the lung showed ground-glass opacities (GGO) sparing the lung periphery in $41 \%$ of episodes, or displaying a mosaic pattern (29\%), or being nearly homogeneous (24\%), GGO associated with air-space consolidation (21\%), associated with cystic formation (21\%), associated with linear-reticular opacities (18\%), patchily and irregularly distributed (15\%), associated with solitary or multiple nodules (9\%) and associated with parenchymal cavity lesions (6\%).

In HIV-uninfected patients consolidations and GGO have been reported more frequently [80]. Interestingly, the study by Mu et al.[83] investigated the relationship between radiological stages (early: early normal or nearly normal on chest x-ray or bilateral diffuse GGO on chest CT; mild: mild bilateral infiltrates on chest x-ray or bilateral diffuse GGO and patchy consolidations on chest CT; late: late bilateral consolidations on chest x-ray or bilateral predominant consolidations on chest CT) and PcP prognoses in 105 HIV-uninfected PcP immunocompromised patients. According to the chest HRCT, 40 cases were at early stage, showing bilateral diffuse GGO, and the case fatality rate (CFR) was $20.0 \%$ ( $P>0.05$ ); 34 cases were at mid stage, showing bilateral diffuse GGO and patchy consolidations, and the CFR was $47.1 \%$ ( $P>0.05$ ); finally, 10 cases were at late stage, showing predominant consolidations in bilateral lung fields, and the CFR was $80.0 \%(P<0.05 T$ The authors described other radiographic findings such as bilateral diffuse GGO with mosaic signs and consolidations, pleural effusions, small nodules, aerothorax, pneumomediastinum, pneumohypoderma, cystic lesions and thickened lobular septa.

\section{Microbiological Diagnosis}

P. jirovecii is difficult to isolate or culture with conventional microbiological methods. 
However, in a recent study by Schildgen et al.[84] it was successfully cultured and propagated from a positive BAL sample. Propagation was possible in CuFi-8 cells, derived from the bronchus of a patient with cystic fibrosis, and EpiAirway cells, derived from human tracheal/bronchial epithelial cells. Unfortunately, no other study has been able to replicate this method of propagation[16].

The most frequently used respiratory samples for PcP diagnosis in HIV-infected patients are induced sputum (less invasive but with low sensitivity) or BAL (higher diagnostic yield). It is known that the immunosuppression profile influences the Pneumocystis load in the infection[51,68], HIV-uninfected patients have a lower burden of organisms and so may present false negative results. PcP diagnosis in HIVuninfected patients requires invasive samples such as BAL or lung biopsies. Other noninvasive samples such as spontaneous sputum, nasopharyngeal aspirate (NA), and oropharyngeal washing (OW) may be useful in the diagnosis of pneumocystis. Of course, their sensibility raises to $75 \%$ when analysed together with molecular tests such as PCR compared to microscopy[85-87].

\subsection{Microscopy}

The gold standard for the microbiological diagnosis of $P$. jirovecii is the microscopic observation of the microorganism in respiratory samples. Staining methods include Grocott-Gomori methenamine silver, toluidine blue-O, calcofluor white, Giemsa stain, and Diff-Quik. Cystic forms are more often observed with the first three methods, whereas trophic forms with the last two methods [88].

In HIV-infected patients with higher microorganism burden, rapid detection by indirect immunofluorescence assay (IFA) with monoclonal antibodies shows high sensitivity 
and specificity in BAL (99\% and 100\% respectively) or induced sputum (50\% and $100 \%$ respectively) using other staining methods as a gold standard. This assay facilitates the identification of both cystic and trophic forms [89]. However, in HIV-uninfected patients with a low microorganism burden, microscopy of BAL is less sensitive; these patients could benefit from the use of molecular techniques[90].

Figure 3 shows a representative microscopic observation of a typical BAL sample.

\subsection{Molecular Diagnosis}

Conventional PCR and real-time PCR assays can detect $P$. jirovecii DNA in various samples, including induced sputum, oral washings, nasopharyngeal aspirates, nasal swabs, BAL, and lung tissue these techniques provide a rapid diagnosis of PcP and help in the initiation of prompt therapy [91]. Molecular assays can also quantify Pneumocystis in clinical samples, and may help in monitoring the effectiveness of antifungal therapy and in differentiating colonization from infection[92]. The established method involves the detection of the mitochondrial large-subunit ribosomal RNA of $P$. jirovecii [93], both in HIV-infected and HIV-uninfected individuals. The main limitation of molecular techniques is the lack of standardization. Further studies are needed before these assays can be incorporated into routine clinical practice. However, molecular techniques improve the diagnostic yield for PcP, provide rapid diagnosis and have been applied to minimally invasive clinical specimens.

Figure 4 shows a tentative algorithm for the microbiological diagnosis of PcP.

\subsection{Differentiation between Colonization and Active Infection}

Several studies have tried to discriminate between colonization and active infection. Luois et al. [39] carried out a composite diagnosis of PcP based on clinical, radiological 
patterns and microbiological results (microscopic examination and quantitative PCR (qPCR) performed on the BAL fluids) from 1003 patients with pneumonia. The authors divided the BAL sample into four groups: a) definite PcP (microscopic demonstration of trophic or cyst forms); b) probable PcP (clinical PcP including outcome after antiPneumocystis therapy and radiological pattern supporting the diagnosis of PcP and positive qPCR but negative microscopic observation of Pneumocystis forms; c)

Pneumocystis colonization (absence of clinical and radiological evidence of PcP but positive qPCR and negative microscopic observation of Pneumocystis forms; d) lack of Pneumocystis infection (absence of clinical data supporting the diagnosis of PcP and absence of positive qPCR or a positive microscopy observation). The rate of colonization was $4 \%$ among 180 HIV-infected patients and $12 \%$ among 823 HIVuninfected patients. The authors suggested using a qPCR cut-off of $1.5 \times 10^{4}$ copies $/ \mathrm{mL}$ (100\% sensitivity and specificity) to distinguish colonization from infection in HIVinfected patients. For HIV-uninfected patients, cut-off values of $2.87 \times 10^{4}$ copies $/ \mathrm{mL}$ and $3.39 \times 10^{4}$ copies/mL obtained $100 \%$ specificity and sensitivity respectively. HIVinfected patients developed PcP with a lower fungal burden compared to HIVuninfected patients.

More recently, Fauchier et al. [38] evaluated the cycle threshold $\left(C_{T}\right)$ values (the number of PCR cycles after which the reaction is considered positive) obtained by qPCR, which are correlated with the fungal burden in the sample, in order to differentiate between colonization and PcP on respiratory samples (sputum, induced sputum, bronchoalveolar lavage [BAL] fluid) from immunocompromised patients with respiratory symptoms. Considering the receiver operating characteristic curve (ROC), the authors found that: 
- $a C_{T}$ value of 32 discriminated between colonization and pneumonia with $72 \%$ of sensitivity and $75 \%$ of specificity (area under the ROC curve [AUC], 0.88);

- in HIV-infected patients, a $\mathrm{C}_{\mathrm{T}}$ value of 27 excluded colonization with a sensitivity of $74 \%$ and a specificity of $100 \%$ (AUC, 0.90 );

- in HIV-uninfected patients, a $\mathrm{C}_{\mathrm{T}}$ value of 35 excluded colonization with a sensitivity of $80 \%$ and a specificity of $60 \%$ (AUC, 0.72 ).

Although these data suggest the utility of qPCR cut-offs to distinguish colonization from infection, they cannot be applied universally. Clinicians should always consider the fungal load variability due to patients characteristics (HIV-infected, HIV-uninfected or degree of immunosuppression), specimen type (invasive or non-invasive) and sample quality.

\section{Biochemical Diagnosis}

\subsection{Serum detection of (1-3)- $\beta$-D-Glucan}

The main component of the cell wall in $P$. jirovecii cysts is the (1-3)- $\beta$-D-glucan (BG), this polysaccharide is released into the circulation during Pneumocystis infection in detectable quantities. The study by Son et al.[94] that compared blood levels of BG in patients with PCP, patients with other diseases (like candidemia, chronic disseminated candidiasis, invasive aspergillosis, mucormycosis and tuberculosis) and in healthy volunteers found that at a cut-off value $>31.25 \mathrm{pg} / \mathrm{mL}$, which is highly sensitive for PcP versus tuberculosis plus healthy volunteers at the expense of specificity, BG had a sensitivity of $92 \%$ and a specificity of $55 \%$. More recently, Lahmer et al.[95] investigated the usefulness of serum BG in mechanically ventilated HIV-uninfected patients with ARDS suspected of having PcP. The detection of serum BG showed an 
overall sensitivity of $92 \%$, and specificity of $84 \%$ for PcP diagnosis, with a high negative predictive value. Interestingly, a bivariate meta-analysis and systematic review published in 2015 analyzed 33 studies on the role of serum BG in the diagnosis of PcP in HIV-infected and HIV-uninfected patients. The authors found that in HIV-infected patients a negative serum BG was sufficient for ruling out PcP, as confirmed in other studies[96,97]. Conversely, in HIV-uninfected patients results of serum BG should be interpreted in parallel with clinical and radiological findings[98].

Although these studies reported that the detection of this polysaccharide in the serum has a specificity of $96 \%$ and a sensitivity of $87 \%$ [99], it is not a specific biomarker of PcP. Its use is limited by the lack of a standardized detection method, the fact that extraneous factors (e.g., immunoglobulins) may cause false-positive results and the fact that high values cannot distinguish between different fungal infections [100]. For these reasons, the use of $B G$ is recommended only in combination with other diagnostic tests.

Figure 4 shows a tentative algorithm for the diagnosis of PcP.

\subsection{S-adenosyl methionine and other biomarkers}

S-adenosyl methionine (SAM) is a molecule that $P$. jirovecii cannot synthesize, but necessary for its metabolism. It is an essential intermediate for protein and nucleic acid methylation, folate metabolism, and polyamine synthesis. $P$. jirovecii therefore requires exogenous SAM and in a study of rats it was observed that plasma SAM concentration was inversely correlated with the lung $P$. jirovecii count [101]. Subsequent testing in human PcP also revealed low plasma SAM concentrations during infection with return to normal values after treatment $[102,103]$. 
Recently, the study by Esteves et al.[104] investigated the useful of four serologic biomarkers [(Krebs von den Lungen-6 antigen (KL-6), BG, lactate dehydrogenase (LDH) and SAM ]for the diagnosis of PcP. The authors found that BG was the most promising biomarker, followed by KL-6, LDH and SAM. The combination of BG and KL- 6 showed the highest accuracy, with $94.3 \%$ sensitivity and $89.6 \%$ specificity. The authors recommended their use both in HIV-infected and HIV-uninfected patients. Conversely, despite SAM concentration was slightly decreased in PcP cases, the sensitivity and specificity analysis demonstrated that SAM failed to discriminate between patients with and without $\mathrm{PcP}$, showing low diagnostic accuracy.

In clinical practice, we recommend the use of biomarkers in association with other specific diagnostic tests for Pneumocystis that complement the interpretation of clinical and radiological data. Although biomarkers and molecular assays are important tools for identifying PcP, the lack of standardized methods makes their implementation difficult in routine clinical practice.

\section{Therapy}

Table 2 summarizes the main recommendations for PcP treatment in HIV-infected and HIV-uninfected patients. Furthermore, details regarding PcP therapy (first line and alternative treatments) and prophylaxis in HIV-infected patients have been provided by Huang et al. [105] in a recently published review covering the main areas of the topic.

Some points regarding additional or alternative therapies in PcP are worthy of importance:

- Adjunctive corticosteroid therapy should be started as early as possible in HIV- 
infected patients with moderate-to-severe PcP due to its benefits in terms of survival [106]. However, adjunctive corticosteroid therapy is not indicated in HIV-infected patients with mild-to-moderate PcP.

- Due to the conflicting results regarding their benefit, glucocorticoids are not recommended in HIV-uninfected patients with PcP. According to current guidelines, the decision to add corticosteroids in HIV-uninfected patients with PcP and respiratory failure should be made on a case by case basis[107].

- Folinic acid supplements are contraindicated in HIV-infected patients with PcP because of the increased risk of treatment failure and death $[17,108]$.

- Clinical experience regarding the use of caspofungin in severe PcP is limited, controversial and based on case reports of severe PcP successfully treated with a combination of low-dose cotrimoxazole and caspofungin in different populations[109-112]. These data suggest the need for future randomized clinical trials.

- Cases of treatment failure with cotrimoxazole and dapsone have been associated with mutations in the DHPS gene of $P$. jirovecii [113-117]. However, research results are unclear and there is only limited information regarding these mutations and their association with outcomes and therapy. Moreover, prophylaxis with sulfamethoxazole may be a risk factor for DHPS mutations $[118,119]$.

- Corticosteroids are recommended for the treatment of paradoxical or unmasked PcP-IRIS [70].

- The use of clindamycin and primaquine as salvage therapy is not currently recommended because the data regarding their efficacy are insufficient. 
However, they may be recommended in cases in which the first and alternative therapies cannot be administered or are not tolerated[17].

\section{Prevention of exposure and disease}

Although there is evidence of the presence of $P$. jirovecii in the air in areas where infected patients reside and of transmission through interpersonal contact[21,22], and although contact between severely immunocompromised patients and patients with confirmed Pneumocystis infection should be avoided, there are insufficient data to support the practice of isolation of patients with PcP in routine clinical practice[17].

\section{1.- Primary and secondary prophylaxis}

Table 3 summarizes the primary and secondary prophylaxis in HIV-infected and HIVuninfected patients.

- Primary prophylaxis should be discontinued in HIV-infected patients when the CD4 count increases from $<200 \mathrm{cell} / \mathrm{mm}^{3}$ to $\geq 200 \mathrm{cell} / \mathrm{mm}^{3}$ for at least 3 months in response to ART therapy or when the CD4 count is 100-200 cell/ $\mathrm{mm}^{3}$ and the viral load suppressed[120].

- Secondary prophylaxis should be discontinued in HIV-infected patients when the CD4 count increases from $<200$ cell $/ \mathrm{mm}^{3}$ to $\geq 200$ cell $/ \mathrm{mm}^{3}$ for at least 3 months in response to ART and HIV-viral load is undetectable over 3 months. [121].

- There is no consensus about secondary prophylaxis in HIV-uninfected patients. However, it is recommended to continue secondary prophylaxis until immunosuppression ends in patients with autoimmune disease, solid-organ 
transplantation, hematological malignancies, and in stem cell transplant recipients [90].

\section{Conclusion}

Although the incidence of PcP is decreasing in patients with HIV, principally because of ART introduction, several major concerns persist in different areas. Notably, there are many patients with unknown HIV infection at the time of PcP diagnosis; many patients do not receive ART or are non-compliant with the therapy; finally there is a rising incidence of patients who are immunocompromised for reasons other than HIV infection. These concerns are compounded by difficulties with PCP diagnosis.

\section{Expert opinion}

During recent years, the scientific community has made significant progress in the epidemiology, diagnosis and management of PcP. However, many questions remain unresolved regarding our understanding of the pathophysiology of Pneumocystis infection, especially in relation to the microorganism-host interaction. The reservoir of Pneumocystis infection has not yet been identified and the mechanism of transmission and infection are not entirely clear; nor has an ideal diagnostic strategy been defined. For this reason, it is important that the research topics listed below be explored in the coming years.

First, epidemiological studies are needed to investigate the global burden of PcP and its attributable mortality. Due to the differences in the study populations, biological samples, and microbiological tests, observational studies should be carried out to assess the rate of Pneumocystis colonization in HIV-infected and HIV-uninfected 
patients. Moreover, prospective studies are required to identify risk factors for PcP, mostly in the "new" group of HIV-uninfected patients, and to recognize patients who would truly benefit from prophylaxis.

The main issue regarding $P$. jirovecii diagnosis is the difficulty of isolating or culturing the pathogen with conventional microbiological methods. Studies on accelerated diagnosis, through rapid and non-invasive molecular techniques, would make it possible to differentiate $P$. jirovecii colonization from infection, and thus allow prompt initiation of targeted therapies. A comparison between current treatment strategy and an approach integrating clinical stratification with old and new biomarkers could provide important strategic insights. Finally, the role of caspofungin in severe PcP should be assessed in randomized clinical trials.

\subsection{Five-year view}

The widespread use of antiretroviral and prophylactic therapy in HIV-infected patients has reduced the incidence of PCP in this population. However, the growing incidence of Pneumocystis infection in HIV-uninfected patients (those receiving chronic corticosteroids, those with hematological or solid malignancies, transplant recipients, and those receiving immunomodulatory or biological therapy) suggests the need for new studies to define the true scale of the disease. Currently, in-hospital mortality rates are very high: $15 \%$ for HIV-infected patients and $50 \%$ in some HIV-uninfected patients. Early identification of patients at risk for PcP and the development of standardized microbiological diagnostic methods for early Pneumocystis detection could facilitate patient management and thus improve their short and long termoutcomes. 


\section{Funding}

The study was funded by Ciber de Enfermedades Respiratorias (CibeRes

CB06/06/0028), 2009 Support to Research Groups of Catalonia 911, IDIBAPS.

\section{Declaration of interest}

J M Miro has received consulting honoraria and/or research grants from AbbVie,

Bristol-Myers Squibb, Cubist, Novartis, Gilead Sciences, and ViiV outside the submitted work. The authors have no other relevant affiliations or financial involvement with any organization or entity with a financial interest in or financial conflict with the subject matter or materials discussed in the manuscript apart from those disclosed.

\section{Reviewer disclosures}

Peer reviewers on this manuscript have no relevant financial or other relationships to disclose.

\section{Author contributions}

All authors were involved in the content development of the manuscript, reviewed all drafts and approved the final version. The authors take full responsibility for the content of this article.

\section{Acknowledgments}

C Cillóniz is a recipient of an ERS Short Term Fellowship and Postdoctoral Grant "Strategic plan for research and innovation in health-PERIS 2016-2020". J M Miro received a personal 80:20 research grant from the Institut d'Investigacions Biomèdiques August Pi i Sunyer (IDIBAPS), Barcelona, Spain, during 2017-19. 


\section{References}

[1] Harpaz R, Dahl RM, Dooling KL. Prevalence of Immunosuppression Among US Adults, 2013. JAMA. 2016;316:2547-2548.

[2] Linden PK. Approach to the immunocompromised host with infection in the intensive care unit. Infect. Dis. Clin. North Am. 2009;23:535-556.

[3] Rouyer M, Stoclin A, Blanc F-X. [Pneumocystis pneumonia in HIV-negative adults]. Rev Mal Respir. 2015;32:985-990.

[4] Bienvenu A-L, Traore K, Plekhanova I, et al. Pneumocystis pneumonia suspected cases in 604 non-HIV and HIV patients. Int. J. Infect. Dis 2016;46:11-17.

[5] Maini R, Henderson KL, Sheridan EA, et al. Increasing Pneumocystis pneumonia, England, UK, 2000-2010. Emerging Infect. Dis. 2013;19:386-392.

[6] Morris A, Norris KA. Colonization by Pneumocystis jirovecii and its role in disease. Clin. Microbiol. Rev. 2012;25:297-317.

[7] Alvaro-Meca A, Palomares-Sancho I, Diaz A, et al. Pneumocystis pneumonia in HIV-positive patients in Spain: epidemiology and environmental risk factors. J Int AIDS Soc. 2015;18:19906.

[8] Kotani T, Katayama S, Miyazaki Y, et al. Risk Factors for the Mortality of Pneumocystis jirovecii Pneumonia in Non-HIV Patients Who Required Mechanical Ventilation: A Retrospective Case Series Study. Biomed Res Int. 2017;2017:7452604.

[9] Liu Y, Su L, Jiang S-J, et al. Risk factors for mortality from pneumocystis carinii pneumonia (PCP) in non-HIV patients: a meta-analysis. Oncotarget. 2017;8:59729-59739.

[10] Asai N, Motojima S, Ohkuni Y, et al. Clinical Manifestations and Prognostic Factors of Pneumocystis jirovecii Pneumonia without HIV. Chemotherapy. 2017;62:343-349.

[11] Huang X, Weng L, Yi L, et al. [Clinical features of acute respiratory failure due to pneumocystis pneumonia in non-HIV immunocompromised patients].

Zhonghua Yi Xue Za Zhi. 2016;96:3057-3061.

[12] Weng L, Huang X, Chen L, et al. Prognostic factors for severe Pneumocystis jiroveci pneumonia of non-HIV patients in intensive care unit: a bicentric retrospective study. BMC Infect. Dis. 2016;16:528.

[13] Avino LJ, Naylor SM, Roecker AM. Pneumocystis jirovecii Pneumonia in the Non-HIV-Infected Population. Ann Pharmacother. 2016;50:673-679.

[14] Alanio A, Bretagne S. Pneumocystis jirovecii detection in asymptomatic patients: what does its natural history tell us? F1000Res. 2017;6:739. 
[15] Wakefield AE, Lindley AR, Ambrose HE, et al. Limited asymptomatic carriage of Pneumocystis jiroveci in human immunodeficiency virus-infected patients. J. Infect. Dis. 2003;187:901-908.

[16] Liu Y, Fahle GA, Kovacs JA. Inability to Culture Pneumocystis jirovecii. MBio. 2018;9:pii: e00939-18.

[17] PCP Adult and Adolescent Opportunistic Infection [Internet]. AIDSinfo. [cited $2018 \mathrm{Jul}$ 4]. Available from: https://aidsinfo.nih.gov/guidelines/html/4/adultand-adolescent-opportunistic-infection/321/pcp.

[18] Ng VL, Yajko DM, Hadley WK. Extrapulmonary pneumocystosis. Clin. Microbiol. Rev. 1997;10:401-418.

[19] Vargas SL, Hughes WT, Wakefield AE, et al. Limited persistence in and subsequent elimination of Pneumocystis carinii from the lungs after P. carinii pneumonia. J. Infect. Dis. 1995; 172:506-510.

[20] Valade S, Azoulay E, Damiani C, et al. Pneumocystis jirovecii airborne transmission between critically ill patients and health care workers. Intensive Care Med. 2015;41:1716-1718.

[21] Choukri F, Menotti J, Sarfati C, et al. Quantification and spread of Pneumocystis jirovecii in the surrounding air of patients with Pneumocystis pneumonia. Clin. Infect. Dis. 2010;51:259-265.

[22] Le Gal S, Pougnet L, Damiani C, et al. Pneumocystis jirovecii in the air surrounding patients with Pneumocystis pulmonary colonization. Diagn. Microbiol. Infect. Dis. 2015;82:137-142.

[23] Pougnet L, Grall A, Moal M-C, et al. Pneumocystis jirovecii Exhalation in the Course of Pneumocystis Pneumonia Treatment. Infect Control Hosp Epidemiol. 2018;39:627-630.

[24] Rabodonirina M, Vanhems P, Couray-Targe S, et al. Molecular evidence of interhuman transmission of Pneumocystis pneumonia among renal transplant recipients hospitalized with HIV-infected patients. Emerging Infect. Dis. 2004;10:1766-1773.

[25] Yazaki H, Goto N, Uchida K, et al. Outbreak of Pneumocystis jiroveci pneumonia in renal transplant recipients: P. jiroveci is contagious to the susceptible host. Transplantation. 2009;88:380-385.

[26] Davey EL, Colombo RE, Fiorentino C, et al. Pneumocystis colonization in asthmatic patients not receiving oral corticosteroid therapy. J. Investig. Med. 2017;65:800-802.

[27] Morris A, Wei K, Afshar K, et al. Epidemiology and clinical significance of pneumocystis colonization. J. Infect. Dis. 2008;197:10-17. 
[28] Ponce CA, Gallo M, Bustamante R, et al. Pneumocystis colonization is highly prevalent in the autopsied lungs of the general population. Clin. Infect. Dis. 2010;50:347-353.

[29] Gutiérrez S, Respaldiza N, Campano E, et al. Pneumocystis jirovecii colonization in chronic pulmonary disease. Parasite. 2011;18:121-126.

[30] Vargas SL, Ponce CA, Sanchez CA, et al. Pregnancy and asymptomatic carriage of Pneumocystis jiroveci. Emerging Infect. Dis. 2003;9:605-606.

[31] Montes-Cano MA, Chabe M, Fontillon-Alberdi M, et al. Vertical transmission of Pneumocystis jirovecii in humans. Emerging Infect. Dis. 2009;15:125-127.

[32] Rojas P, Friaza V, García E, et al. Early Acquisition of Pneumocystis jirovecii Colonization and Potential Association With Respiratory Distress Syndrome in Preterm Newborn Infants. Clin. Infect. Dis. 2017;65:976-981.

[33] Medrano FJ, Montes-Cano M, Conde M, et al. Pneumocystis jirovecii in general population. Emerging Infect. Dis. 2005;11:245-250.

[34] Vargas SL, Pizarro P, López-Vieyra M, et al. Pneumocystis colonization in older adults and diagnostic yield of single versus paired noninvasive respiratory sampling. Clin. Infect. Dis. 2010;50:e19-21.

[35] Morris A, Sciurba FC, Lebedeva IP, et al. Association of chronic obstructive pulmonary disease severity and Pneumocystis colonization. Am. J. Respir. Crit. Care Med. 2004;170:408-413.

[36] Sivam S, Sciurba FC, Lucht LA, et al. Distribution of Pneumocystis jirovecii in lungs from colonized COPD patients. Diagn. Microbiol. Infect. Dis.

2011;71:24-28.

[37] Global Initiative for Chronic Obstructive Lung Disease [Internet]. Global Initiative for Chronic Obstructive Lung Disease - GOLD. [cited 2018 Aug 28]. Available from: https://goldcopd.org/.

[38] Fauchier T, Hasseine L, Gari-Toussaint M, et al. Detection of Pneumocystis jirovecii by Quantitative PCR To Differentiate Colonization and Pneumonia in Immunocompromised HIV-Positive and HIV-Negative Patients. J. Clin. Microbiol. 2016;54:1487-1495.

[39] Louis M, Guitard J, Jodar M, et al. Impact of HIV Infection Status on Interpretation of Quantitative PCR for Detection of Pneumocystis jirovecii. J. Clin. Microbiol. 2015;53:3870-3875.

[40] Taylor SM, Meshnick SR, Worodria W, et al. Low prevalence of Pneumocystis jirovecii lung colonization in Ugandan HIV-infected patients hospitalized with non-Pneumocystis pneumonia. Diagn. Microbiol. Infect. Dis. 2012;72:139-143.

[41] Davis JL, Welsh DA, Beard CB, et al. Pneumocystis colonisation is common among hospitalised HIV infected patients with non-Pneumocystis pneumonia. Thorax. 2008;63:329-334. 
[42] Gutiérrez S, Morilla R, León JA, et al. High prevalence of Pneumocystis jiroveci colonization among young HIV-infected patients. J Adolesc Health. 2011;48:103-105.

[43] Mekinian A, Durand-Joly I, Hatron P-Y, et al. Pneumocystis jirovecii colonization in patients with systemic autoimmune diseases: prevalence, risk factors of colonization and outcome. Rheumatology (Oxford). 2011;50:569577.

[44] Cilloniz C, Torres A, Polverino E, et al. Community-acquired lung respiratory infections in HIV-infected patients: microbial aetiology and outcome. Eur. Respir. J. 2014;43:1698-1708.

[45] López-Sánchez C, Falcó V, Burgos J, et al. Epidemiology and long-term survival in HIV-infected patients with Pneumocystis jirovecii pneumonia in the HAART era: experience in a university hospital and review of the literature. Medicine (Baltimore). 2015;94:e681.

[46] Limper AH, Adenis A, Le T, et al. Fungal infections in HIV/AIDS. Lancet Infect Dis. 2017;17:e334-e343.

[47] Nakanjako D, Kiragga AN, Musick BS, et al. Frequency and impact of suboptimal immune recovery on first-line antiretroviral therapy within the International Epidemiologic Databases to Evaluate AIDS in East Africa. AIDS. 2016;30:1913-1922.

[48] Miller RF, Huang L, Walzer PD. Pneumocystis pneumonia associated with human immunodeficiency virus. Clin. Chest Med. 2013;34:229-241.

[49] Bongomin F, Gago S, Oladele RO, et al. Global and Multi-National Prevalence of Fungal Diseases-Estimate Precision. J Fungi (Basel) [Internet]. 2017 [cited 2019 Mar 7];3. Available from:

https://www.ncbi.nlm.nih.gov/pmc/articles/PMC5753159/.

[50] Armstrong-James D, Meintjes G, Brown GD. A neglected epidemic: fungal infections in HIV/AIDS. Trends Microbiol. 2014;22:120-127.

[51] Roux A, Canet E, Valade S, et al. Pneumocystis jirovecii pneumonia in patients with or without AIDS, France. Emerging Infect. Dis. 2014;20:1490-1497.

[52] Wasserman S, Engel ME, Griesel R, et al. Burden of pneumocystis pneumonia in HIV-infected adults in sub-Saharan Africa: a systematic review and metaanalysis. BMC Infect. Dis. 2016;16:482.

[53] Kim JH, Psevdos G, Gonzalez E, et al. All-cause mortality in hospitalized HIVinfected patients at an acute tertiary care hospital with a comprehensive outpatient HIV care program in New York City in the era of highly active antiretroviral therapy (HAART). Infection. 2013;41:545-551.

[54] Siegel M, Masur H, Kovacs J. Pneumocystis jirovecii Pneumonia in Human Immunodeficiency Virus Infection. Semin Respir Crit Care Med. 2016;37:243256. 
[55] Buchacz K, Lau B, Jing Y, et al. Incidence of AIDS-Defining Opportunistic Infections in a Multicohort Analysis of HIV-infected Persons in the United States and Canada, 2000-2010. J. Infect. Dis. 2016;214:862-872.

[56] Coelho L, Cardoso SW, Amancio RT, et al. Trends in AIDS-defining opportunistic illnesses incidence over 25 years in Rio de Janeiro, Brazil. PLoS ONE. 2014;9:e98666.

[57] Wang H-W, Lin C-C, Kuo C-F, et al. Mortality predictors of Pneumocystis jirovecii pneumonia in human immunodeficiency virus-infected patients at presentation: Experience in a tertiary care hospital of northern Taiwan. J Microbiol Immunol Infect. 2011;44:274-281.

[58] Walzer PD, Evans HER, Copas AJ, et al. Early predictors of mortality from Pneumocystis jirovecii pneumonia in HIV-infected patients: 1985-2006. Clin. Infect. Dis. 2008;46:625-633.

[59] Wickramasekaran RN, Jewell MP, Sorvillo F, et al. The changing trends and profile of pneumocystosis mortality in the United States, 1999-2014. Mycoses. 2017;

[60] Elsegeiny W, Eddens T, Chen K, et al. Anti-CD20 antibody therapy and susceptibility to Pneumocystis pneumonia. Infect. Immun. 2015;83:2043-2052.

[61] Kapoor TM, Mahadeshwar P, Nguyen S, et al. Low prevalence of Pneumocystis pneumonia in hospitalized patients with systemic lupus erythematosus: review of a clinical data warehouse. Lupus. 2017;961203317703494.

[62] Mecoli CA, Saylor D, Gelber AC, et al. Pneumocystis jiroveci pneumonia in rheumatic disease: a 20-year single-centre experience. Clin. Exp. Rheumatol. 2017;

[63] Fillâtre P, Revest M, Belaz S, et al. [Pneumocystosis in non-HIV-infected immunocompromised patients]. Rev Med Interne. 2016;37:327-336.

[64] Fillatre P, Decaux O, Jouneau S, et al. Incidence of Pneumocystis jiroveci pneumonia among groups at risk in HIV-negative patients. Am. J. Med. 2014;127:1242.e11-17.

[65] Azoulay E, Roux A, Vincent F, et al. A Multivariable Prediction Model for Pneumocystis jirovecii Pneumonia in Hematology Patients with Acute Respiratory Failure. Am. J. Respir. Crit. Care Med. 2018;

[66] Cordonnier C, Cesaro S, Maschmeyer G, et al. Pneumocystis jirovecii pneumonia: still a concern in patients with haematological malignancies and stem cell transplant recipients. J. Antimicrob. Chemother. 2016;71:2379-2385.

[67] Liu C-J, Lee T-F, Ruan S-Y, et al. Clinical characteristics, treatment outcomes, and prognostic factors of Pneumocystis pneumonia in non-HIV-infected patients. Infect Drug Resist. 2019;12:1457-1467. 
[68] Limper AH, Offord KP, Smith TF, et al. Pneumocystis carinii pneumonia. Differences in lung parasite number and inflammation in patients with and without AIDS. Am. Rev. Respir. Dis. 1989;140:1204-1209.

[69] Rego de Figueiredo I, Vieira Alves R, Drummond Borges D, et al. Pneumocystosis pneumonia: A comparison study between HIV and non-HIV immunocompromised patients. Pulmonology. 2019;

[70] Gopal R, Rapaka RR, Kolls JK. Immune reconstitution inflammatory syndrome associated with pulmonary pathogens. Eur Respir Rev. 2017;26.

[71] Mok HP, Hart E, Venkatesan P. Early development of immune reconstitution inflammatory syndrome related to Pneumocystis pneumonia after antiretroviral therapy. Int J STD AIDS. 2014;25:373-377.

[72] Roade Tato L, Burgos Cibrian J, Curran Fábregas A, et al. Immune reconstitution inflammatory syndrome in HIV-infected patients with Pneumocystis jirovecii pneumonia. Enferm. Infecc. Microbiol. Clin. 2017;

[73] Meintjes G, Scriven J, Marais S. Management of the immune reconstitution inflammatory syndrome. Curr HIV/AIDS Rep. 2012;9:238-250.

[74] Montaner JS, Lawson LM, Levitt N, et al. Corticosteroids prevent early deterioration in patients with moderately severe Pneumocystis carinii pneumonia and the acquired immunodeficiency syndrome (AIDS). Ann. Intern. Med. 1990;113:14-20.

[75] Kolditz M, Halank M, Bandt D, et al. Early recurrence of Pneumocystis jiroveci pneumonia in two HIV-infected patients: linking infection relapse and immune reconstitution syndrome. Respirology. 2009;14:910-912.

[76] Achenbach CJ, Harrington RD, Dhanireddy S, et al. Paradoxical immune reconstitution inflammatory syndrome in HIV-infected patients treated with combination antiretroviral therapy after AIDS-defining opportunistic infection. Clin. Infect. Dis. 2012;54:424-433.

[77] Zolopa A, Andersen J, Powderly W, et al. Early antiretroviral therapy reduces AIDS progression/death in individuals with acute opportunistic infections: a multicenter randomized strategy trial. PLoS ONE. 2009;4:e5575.

[78] Zolopa A, Andersen J, Powderly W, et al. Early antiretroviral therapy reduces AIDS progression/death in individuals with acute opportunistic infections: a multicenter randomized strategy trial. PLoS ONE. 2009;4:e5575.

[79] Fujii T, Nakamura T, Iwamoto A. Pneumocystis pneumonia in patients with HIV infection: clinical manifestations, laboratory findings, and radiological features. J. Infect. Chemother. 2007;13:1-7.

[80] Tasaka S, Tokuda H, Sakai F, et al. Comparison of clinical and radiological features of pneumocystis pneumonia between malignancy cases and acquired immunodeficiency syndrome cases: a multicenter study. Intern. Med. 2010;49:273-281. 
[81] Ebner L, Walti LN, Rauch A, et al. Clinical Course, Radiological Manifestations, and Outcome of Pneumocystis jirovecii Pneumonia in HIV Patients and Renal Transplant Recipients. PLoS ONE. 2016;11:e0164320.

[82] Kanne JP, Yandow DR, Meyer CA. Pneumocystis jiroveci pneumonia: highresolution CT findings in patients with and without HIV infection. AJR Am J Roentgenol. 2012;198:W555-561.

[83] Mu X-D, Jia P, Gao L, et al. Relationship between Radiological Stages and Prognoses of Pneumocystis Pneumonia in Non-AIDS Immunocompromised Patients. Chin. Med. J. 2016;129:2020-2025.

[84] Schildgen V, Mai S, Khalfaoui S, et al. Pneumocystis jirovecii can be productively cultured in differentiated $\mathrm{CuFi}-8$ airway cells. MBio. 2014;5:e01186-14.

[85] Helweg-Larsen J, Jensen JS, Benfield T, et al. Diagnostic use of PCR for detection of Pneumocystis carinii in oral wash samples. J. Clin. Microbiol. 1998;36:2068-2072.

[86] Juliano JJ, Barnett E, Parobek CM, et al. Use of Oropharyngeal Washes to Diagnose and Genotype Pneumocystis jirovecii. Open Forum Infect Dis. 2015;2:ofv080.

[87] van Halsema C, Johnson L, Baxter J, et al. Short Communication: Diagnosis of Pneumocystis jirovecii Pneumonia by Detection of DNA in Blood and Oropharyngeal Wash, Compared with Sputum. AIDS Res. Hum. Retroviruses. 2016;32:463-466.

[88] Lamoth F, Alexander BD. Nonmolecular methods for the diagnosis of respiratory fungal infections. Clin. Lab. Med. 2014;34:315-336.

[89] Procop GW, Haddad S, Quinn J, et al. Detection of Pneumocystis jiroveci in Respiratory Specimens by Four Staining Methods. J. Clin. Microbiol. 2004;42:3333-3335.

[90] Maertens J, Cesaro S, Maschmeyer G, et al. ECIL guidelines for preventing Pneumocystis jirovecii pneumonia in patients with haematological malignancies and stem cell transplant recipients. J. Antimicrob. Chemother. 2016;71:23972404.

[91] Alvarez-Martínez MJ, Miró JM, Valls ME, et al. Sensitivity and specificity of nested and real-time PCR for the detection of Pneumocystis jiroveci in clinical specimens. Diagn. Microbiol. Infect. Dis. 2006;56:153-160.

[92] Azoulay E, Bergeron A, Chevret S, et al. Polymerase chain reaction for diagnosing pneumocystis pneumonia in non-HIV immunocompromised patients with pulmonary infiltrates. Chest. 2009;135:655-661.

[93] Wakefield AE, Guiver L, Miller RF, et al. DNA amplification on induced sputum samples for diagnosis of Pneumocystis carinii pneumonia. The Lancet. 1991;337:1378-1379. 
[94] Son H-J, Sung H, Park SY, et al. Diagnostic performance of the (1-3)- $\beta$-Dglucan assay in patients with Pneumocystis jirovecii compared with those with candidiasis, aspergillosis, mucormycosis, and tuberculosis, and healthy volunteers. PLoS ONE. 2017;12:e0188860.

[95] Lahmer T, da Costa CP, Held J, et al. Usefulness of 1,3 Beta-D-Glucan Detection in non-HIV Immunocompromised Mechanical Ventilated Critically Ill Patients with ARDS and Suspected Pneumocystis jirovecii Pneumonia. Mycopathologia. 2017;182:701-708.

[96] Passos AIM, Dertkigil RP, Ramos M de C, et al. Serum markers as an aid in the diagnosis of pulmonary fungal infections in AIDS patients. Braz J Infect Dis. 2017;21:606-612.

[97] Esteves F, Lee C-H, de Sousa B, et al. (1-3)-beta-D-glucan in association with lactate dehydrogenase as biomarkers of Pneumocystis pneumonia (PcP) in HIVinfected patients. Eur. J. Clin. Microbiol. Infect. Dis. 2014;33:1173-1180.

[98] Li W-J, Guo Y-L, Liu T-J, et al. Diagnosis of pneumocystis pneumonia using serum (1-3)- $\beta$-D-Glucan: a bivariate meta-analysis and systematic review. J Thorac Dis. 2015;7:2214-2225.

[99] Karageorgopoulos DE, Qu J-M, Korbila IP, et al. Accuracy of $\beta$-D-glucan for the diagnosis of Pneumocystis jirovecii pneumonia: a meta-analysis. Clin. Microbiol. Infect. 2013;19:39-49.

[100] Onishi A, Sugiyama D, Kogata Y, et al. Diagnostic accuracy of serum 1,3- $\beta$-Dglucan for pneumocystis jiroveci pneumonia, invasive candidiasis, and invasive aspergillosis: systematic review and meta-analysis. J. Clin. Microbiol. 2012;50:7-15.

[101] Merali S, Vargas D, Franklin M, et al. S-adenosylmethionine and Pneumocystis carinii. J. Biol. Chem. 2000;275:14958-14963.

[102] Skelly MJ, Holzman RS, Merali S. S-Adenosylmethionine Levels in the Diagnosis of Pneumocystis carinii Pneumonia in Patients with HIV Infection. Clin Infect Dis. 2008;46:467-471.

[103] Skelly M, Hoffman J, Fabbri M, et al. S-adenosylmethionine concentrations in diagnosis of Pneumocystis carinii pneumonia. Lancet. 2003;361:1267-1268.

[104] Esteves F, Calé SS, Badura R, et al. Diagnosis of Pneumocystis pneumonia: evaluation of four serologic biomarkers. Clin. Microbiol. Infect. 2015;21:379.e1-10.

[105] Huang Y-S, Yang J-J, Lee N-Y, et al. Treatment of Pneumocystis jirovecii pneumonia in HIV-infected patients: a review. Expert Rev Anti Infect Ther. 2017;15:873-892.

[106] Ewald H, Raatz H, Boscacci R, et al. Adjunctive corticosteroids for Pneumocystis jiroveci pneumonia in patients with HIV infection. Cochrane Database Syst Rev. 2015;CD006150. 
[107] Maschmeyer G, Helweg-Larsen J, Pagano L, et al. ECIL guidelines for treatment of Pneumocystis jirovecii pneumonia in non-HIV-infected haematology patients. J. Antimicrob. Chemother. 2016;71:2405-2413.

[108] Safrin S, Lee BL, Sande MA. Adjunctive folinic acid with trimethoprimsulfamethoxazole for Pneumocystis carinii pneumonia in AIDS patients is associated with an increased risk of therapeutic failure and death. J. Infect. Dis. 1994;170:912-917.

[109] Tu G-W, Ju M-J, Xu M, et al. Combination of caspofungin and low-dose trimethoprim/sulfamethoxazole for the treatment of severe Pneumocystis jirovecii pneumonia in renal transplant recipients. Nephrology (Carlton). 2013;18:736-742.

[110] Utili R, Durante-Mangoni E, Basilico C, et al. Efficacy of caspofungin addition to trimethoprim-sulfamethoxazole treatment for severe pneumocystis pneumonia in solid organ transplant recipients. Transplantation. 2007;84:685688.

[111] Lee W-S, Hsueh P-R, Hsieh T-C, et al. Caspofungin salvage therapy in Pneumocystis jirovecii pneumonia. J Microbiol Immunol Infect. 2017;50:547548.

[112] Kim T, Hong H-L, Lee Y-M, et al. Is caspofungin really an effective treatment for Pneumocystis jirovecii pneumonia in immunocompromised patients without human immunodeficiency virus infection? Experiences at a single center and a literature review. Scand. J. Infect. Dis. 2013;45:484-488.

[113] Ponce CA, Chabé M, George C, et al. High Prevalence of Pneumocystis jirovecii Dihydropteroate Synthase Gene Mutations in Patients with a First Episode of Pneumocystis Pneumonia in Santiago, Chile, and Clinical Response to Trimethoprim-Sulfamethoxazole Therapy. Antimicrob. Agents Chemother. $2017 ; 61$.

[114] Valerio A, Tronconi E, Mazza F, et al. Genotyping of Pneumocystis jiroveci pneumonia in Italian AIDS patients. Clinical outcome is influenced by dihydropteroate synthase and not by internal transcribed spacer genotype. J. Acquir. Immune Defic. Syndr. 2007;45:521-528.

[115] Nahimana A, Rabodonirina M, Bille J, et al. Mutations of Pneumocystis jirovecii dihydrofolate reductase associated with failure of prophylaxis. Antimicrob. Agents Chemother. 2004;48:4301-4305.

[116] Suárez I, Roderus L, van Gumpel E, et al. Low prevalence of DHFR and DHPS mutations in Pneumocystis jirovecii strains obtained from a German cohort. Infection. 2017;

[117] Queener SF, Cody V, Pace J, et al. Trimethoprim Resistance of Dihydrofolate Reductase Variants from Clinical Isolates of Pneumocystis jirovecii. Antimicrob Agents Chemother. 2013;57:4990-4998. 
[118] Stein CR, Poole C, Kazanjian P, et al. Sulfa Use, Dihydropteroate Synthase Mutations, and Pneumocystis jirovecii Pneumonia. Emerg Infect Dis. 2004;10:1760-1765.

[119] Alvarez-Martínez MJ, Miró JM, Valls ME, et al. Prevalence of dihydropteroate synthase genotypes before and after the introduction of combined antiretroviral therapy and their influence on the outcome of Pneumocystis pneumonia in HIV1-infected patients. Diagn. Microbiol. Infect. Dis. 2010;68:60-65.

[120] Is It Safe to Discontinue Primary Pneumocystis jiroveci Pneumonia Prophylaxis in Patients with Virologically Suppressed HIV Infection and a CD4 Cell Count $<200$ Cells/ $\mu$ L? Clin Infect Dis. 2010;51:611-619.

[121] Masur H, Kaplan JE, Holmes KK, et al. Guidelines for preventing opportunistic infections among HIV-infected persons--2002. Recommendations of the U.S. Public Health Service and the Infectious Diseases Society of America. Ann. Intern. Med. 2002;137:435-478. 
Table 1. Clinical manifestations, radiographic features and outcomes of Pneumocystis pneumonia in HIV-infected and HIV-uninfected patients

\begin{tabular}{|c|c|}
\hline HIV-infecte & HIV-u \\
\hline Sub-acute onset & Rapid onset \\
\hline Longer symptoms dur & Shorter symp \\
\hline Low-grade feve & $\begin{array}{l}\text { High grade fever and rapid progression to } \\
\text { respiratory failure }\end{array}$ \\
\hline $\begin{array}{l}\text { Bilateral interstitial and alveolar infiltrates } \\
\text { involving perihilar areas }\end{array}$ & h ground-glass opacities \\
\hline $10-20 \%$ requir & $\begin{array}{l}\text { Approximately } 50 \% \text { require ICU } \\
\text { admission }\end{array}$ \\
\hline $\begin{array}{l}\text { Less severe course with a mc } \\
15 \% \text { (range } 10 \%-20 \% \text { ) }\end{array}$ & $\begin{array}{l}\text { Fulminant course with a mortality rate of } \\
30 \%-60 \%\end{array}$ \\
\hline $\begin{array}{l}\text { Prognostic factors: } \\
\text { Acute respiratory failure ( } \mathrm{PaO} 2<60 \mathrm{mmHg} \text {, } \\
\text { A-aO2 gradient) at admission, delay in ICU } \\
\text { admission, need of mechanical ventilation, } \\
\text { marked chest radiographic abnormalities, } \\
\text { pneumothorax, low serum albumin; low } \\
\text { hemoglobin, high LDH, high APACHE II score, } \\
\text { increased age, injection drug use, previous } \\
\text { PCP, pulmonary KS, and coinfections and } \\
\text { comorbidities. }\end{array}$ & $\begin{array}{l}\text { Prognostic factors: } \\
\text { Respiratory failure, pre-existing lung } \\
\text { disease, pneumothorax, lymphopenia, } \\
\text { increased BUN, high lactate } \\
\text { dehydrogenase, low serum albumin, } \\
\text { adjunctive steroid therapy, longer time } \\
\text { from onset of symptoms to diagnosis. }\end{array}$ \\
\hline
\end{tabular}

Abbreviations: HIV, human immunodeficiency virus; ICU, intensive care unit 
Table 2. Recommendation for Pneumocystis pneumonia treatment $(5,87)$

\begin{tabular}{|c|c|}
\hline Population & Recommendation \\
\hline $\begin{array}{l}\text { HIV-infected patients with } \\
\text { moderate-to-severe PCP }\end{array}$ & $\begin{array}{l}\text { *First line: TMP-SMX: } 15-20 \mathrm{mg} / \mathrm{kg} \text { (TMP); } 75-100 \mathrm{mg} / \mathrm{kg}(\mathrm{SMX}) \text { per day, in } 3 \text { or } 4 \text { divided doses for } 21 \text { days } \\
\text { (The dose must be adjusted if there is abnormal renal function). } \\
\text { * Alternatives: } \\
\text { - Pentamidine } 4 \mathrm{mg} / \mathrm{kg} \text { IV once daily (may be reduced to } 3 \mathrm{mg} / \mathrm{kg} \mathrm{IV} \mathrm{once} \mathrm{daily} \mathrm{if} \mathrm{toxicities} \mathrm{arise).} \\
\text { - Primaquine } 30 \mathrm{mg} \text { (base) once daily + (Clindamycin } 600 / 6 \mathrm{~h} \text { or } 900 \mathrm{mg} / 8 \text { ) or ( } 450 \mathrm{mg} / 6 \mathrm{~h} \text { or } 600 \mathrm{mg} / 8 \mathrm{~h} \text { ). } \\
\geq 35 \mathrm{mmHg} \text {. } \\
\text { Doses recommended: days } 1-5: 40 \mathrm{mg} \text { (oral) twice daily; days } 6-10: 40 \mathrm{mg} \text { (oral) daily; days } 11-15 / 20: 20 \mathrm{mg} \text { (oral) } \\
\text { daily. }\end{array}$ \\
\hline HIV-infected patients with & *First line: TMP-SMX: 15-20 mg/kg (TMP); 75-100 mg/kg (SMX) per day, divided in 3 doses for 21 days (oral) \\
\hline
\end{tabular}




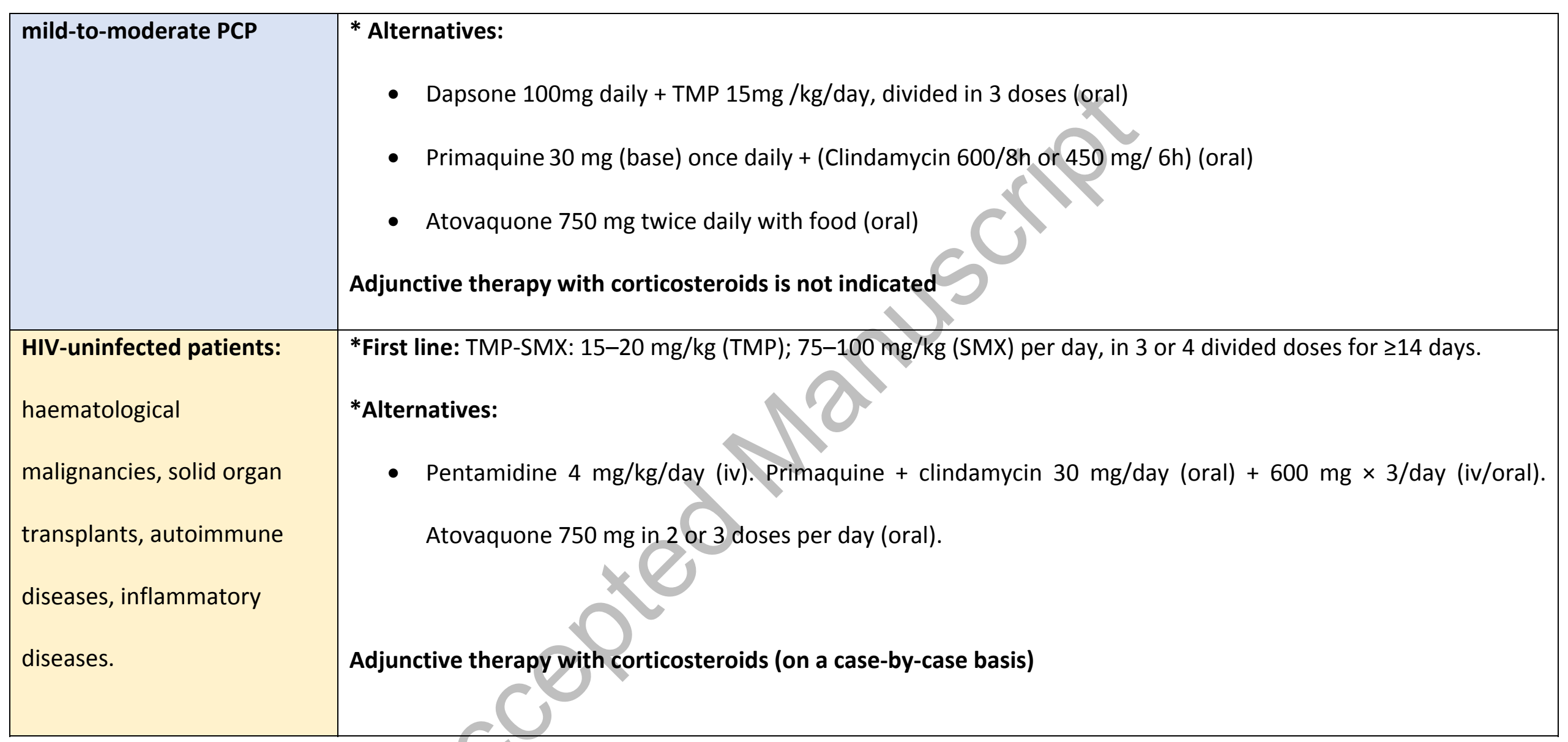

Abbreviations: HIV, human immunodeficiency virus; ICU, intensive care unit; PCP, Pneumocystis pneumonia; SMX, sulfamethoxazole; TMP, trimethoprim. 
Table 3. Prophylaxis of PCP

\begin{tabular}{|c|c|}
\hline \multicolumn{2}{|l|}{ Primary prophylaxis } \\
\hline \multicolumn{2}{|r|}{ HIV-infected patients } \\
\hline \multicolumn{2}{|c|}{$\begin{array}{l}\text { Initiate: if CD4 count }<200 \text { cells } / \mu \mathrm{L}, \mathrm{CD} 4 \text { percentage }<14 \% \text {, oral thrush or relevant concomitant } \\
\text { immunosuppression }\end{array}$} \\
\hline \multicolumn{2}{|c|}{$\begin{array}{l}\text { Stop: if CD4 count > } 200 \text { cells/ } \mu \mathrm{L} \text { over } 3 \text { months or CD4 count 100-200 cells/ } \mu \mathrm{L} \text { and } \mathrm{HIV}-\mathrm{VL} \\
\text { undetectable over } 3 \text { months }\end{array}$} \\
\hline First line & Dose \\
\hline Trimethoprim/sulfamethoxazole & $\begin{array}{l}1 \text { single-strength tablet }(80 \mathrm{mg} / 400 \mathrm{mg}) \text { daily or } \\
1 \text { double-strength tablet }(160 \mathrm{mg} / 800 \mathrm{mg}) \text { daily. }\end{array}$ \\
\hline \multicolumn{2}{|l|}{ Second line } \\
\hline Dapsone & $1 \times 100 \mathrm{mg} /$ day p.o. \\
\hline Atovaquone & $1 \times 1500 \mathrm{mg} /$ day p.o. (with food) \\
\hline Pentamidine aerosols & $300 \mathrm{mg}$ in $6 \mathrm{~mL}$ sterile water,1 inhalation/month \\
\hline \multicolumn{2}{|r|}{ HIV-uninfected patients } \\
\hline First line & \multirow{2}{*}{\begin{tabular}{|c|} 
Dose \\
1 single-strength tablet $(80 \mathrm{mg} / 400 \mathrm{mg})$ daily or \\
1 double-strength tablet $(160 \mathrm{mg} / 800 \mathrm{mg}$ ) daily.
\end{tabular}} \\
\hline Trimethoprim/sulfamethoxazole & \\
\hline \multicolumn{2}{|c|}{ Second line } \\
\hline Dapsone & $2 \times 50 \mathrm{mg} /$ day p.o. \\
\hline Atovaquone & $1 \times 1500 \mathrm{mg} /$ day p.o. (with food) \\
\hline Pentamidine aerosols & $300 \mathrm{mg}$ in $6 \mathrm{~mL}$ of sterile water, 1 inhalation/month \\
\hline \multicolumn{2}{|l|}{ Secondary prophylaxis } \\
\hline \multicolumn{2}{|r|}{ HIV-infected patients } \\
\hline \multicolumn{2}{|c|}{ Stop: if CD4 count > 200 cells/ $\mu \mathrm{L}$ and HIV-VL undetectable over 3 months } \\
\hline Trimethoprim/sulfamethoxazole & $\begin{array}{l}1 \text { single-strength tablet }(80 \mathrm{mg} / 400 \mathrm{mg}) \text { daily or } \\
1 \text { double-strength tablet }(160 \mathrm{mg} / 800 \mathrm{mg}) \text { daily. }\end{array}$ \\
\hline Atovaquone & $1 \times 1500$ mg/day p.o. (with food) \\
\hline Pentamidine aerosols & $300 \mathrm{mg}$ in $6 \mathrm{~mL}$ of sterile water, 1 inhalation/month \\
\hline
\end{tabular}




\section{HIV-uninfected patients}

No general consensus: continuation of the secondary prophylaxis is recommended until the end of the immunosuppression condition. 
Figure 1. PCP in the French population (1990-2010)

Data from a single country study

HIV-infected patients

HIV-uninfected patients

Hematological malignancies $33 \%$

-Tumors 18\%

Inflammatory diseases 15\%

Solidorgan transplants $12 \%$

Nasalitis 10\%

ICU admission 28\%

ICU mortality 15\%

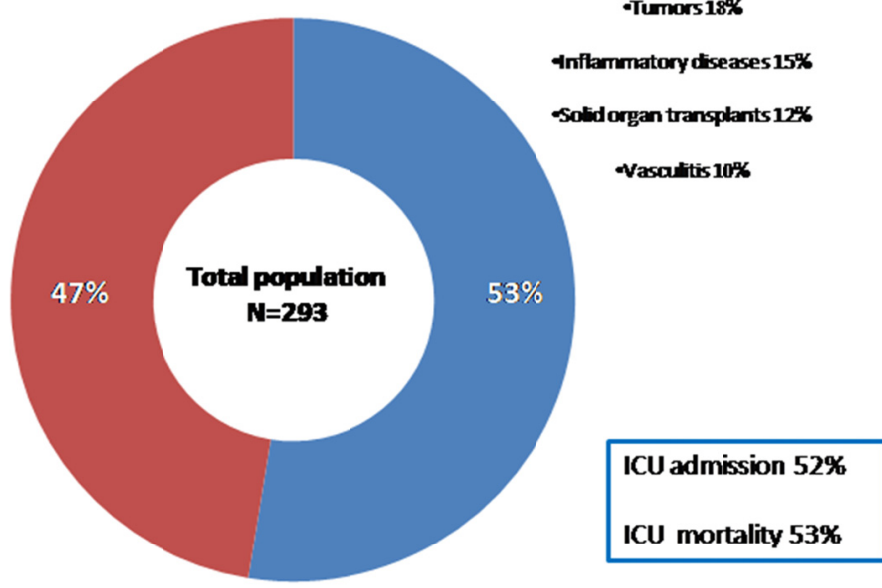

Modifiedfrom Filatre et al Am I Med 2014 Dec;1D(12):1242.e11-17 
a

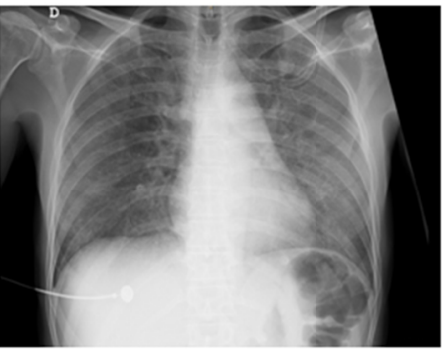

$\mathbf{c}$

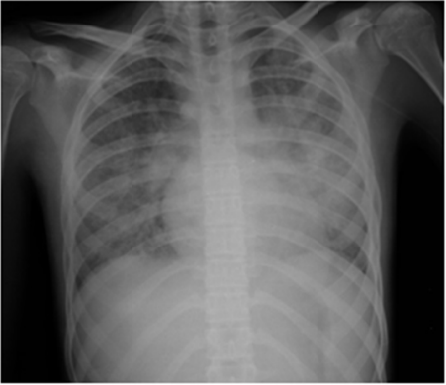

b

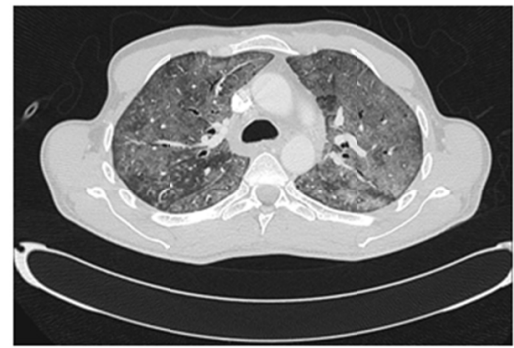

d

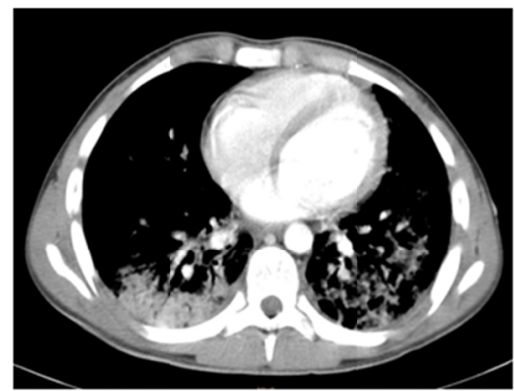

Figure 2. Radiographic imaging of Pneumocystis pneumonia.

(a) A 41-year old man with recent diagnosis of HN and 4 CD4+ T cells/ $/ \mathrm{mm}^{3}$; chest-x-ray on day 1 do not show abnormalities. (b) CT scan on day 1 shows bilateral interstitial infiltrates and ground-glass opacities.

(c) A 16-year old patient with acute myeloid leukemia; chest-x-ray on day 2 shows a bilateral interstitial pattem, cardiomegaly and a consolidation in the mid-basal left lung. (d) CT scan on day 3 shows multiple pulmonary infiltrates with a diffuse and bilateral distribution, consolidations in both lower lobes $(W / R W)$ and a minimum bilateral pleural effusion . 
Figure 3. Microscopic obsenation of bronchoalveolar lavage sample

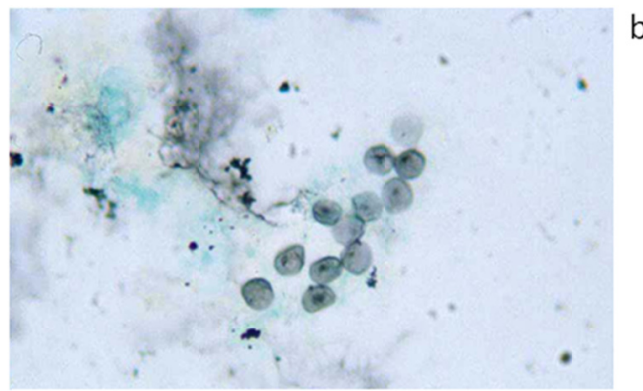

$\mathrm{C}$

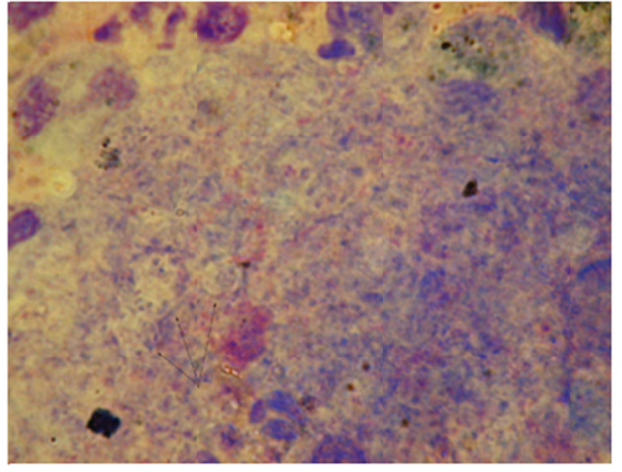

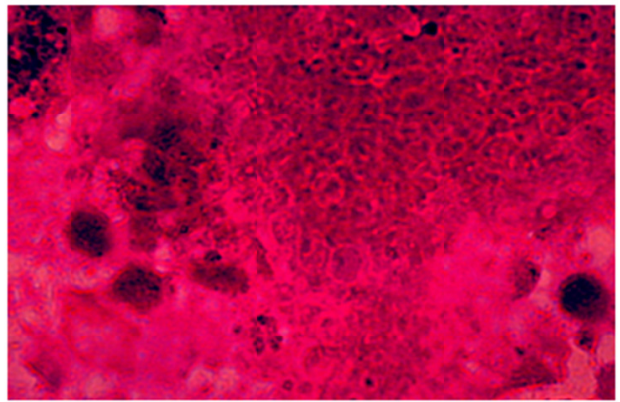

d

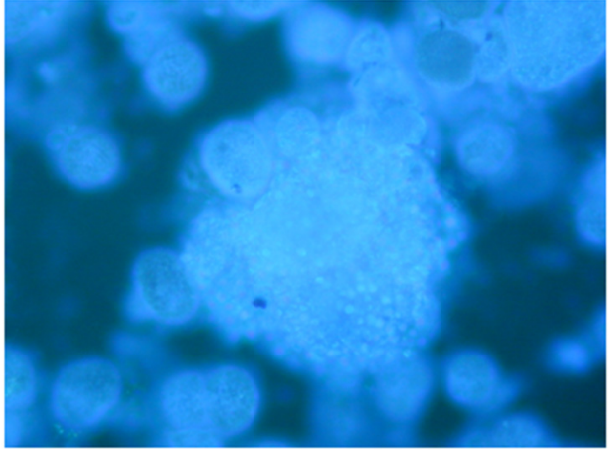

a) Gomorimethamine silver stain; b) Gram stain; c) May-Grunwald Giemsa stain c) Fluorescent Calcofluor-white stain: Cysts are observed in all stains

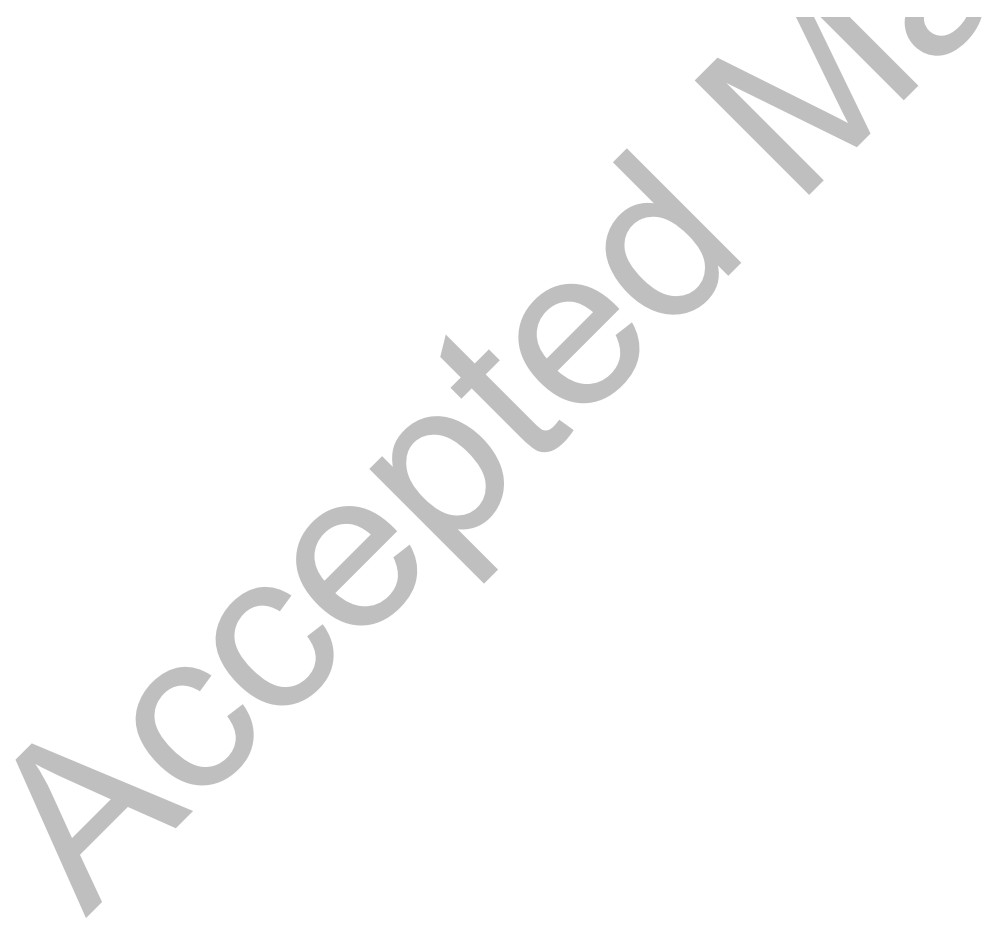


Figure 4. Proposed flow algorithm for the microbiological diagnosis of Pneumocystis pneumonia in HN-infected and HN-urinfected patients

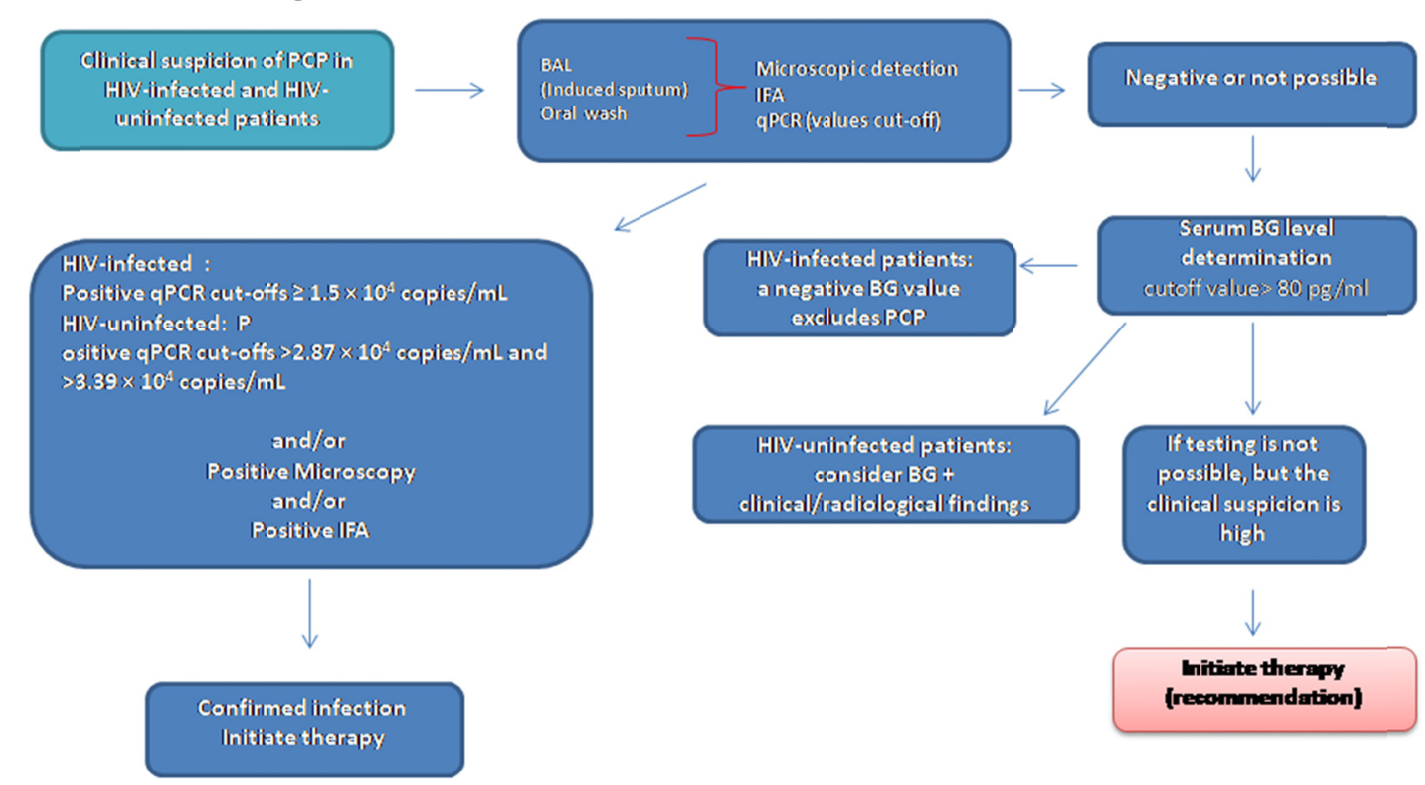

